\title{
Correction to: Manufacturing Zero-Waste COVID-19 \\ Personal Protection Equipment: a Case Study of Utilizing 3D Printing while Employing Waste Material Recycling
}

\author{
Antreas Kantaros ${ }^{1}$ (D) - Nikolaos Laskaris ${ }^{1} \cdot$ Dimitrios Piromalis $^{1} \cdot$ Theodore Ganetsos $^{1}$ \\ Published online: 18 June 2021 \\ (C) Springer Nature Switzerland AG 2021
}

Correction to: Circ.Econ.Sust. https://doi.org/10.1007/s43615-021-00047-8

Unfortunately, the original publication contained a typo in the name of Theodore Ganetsos. This has been corrected.

The online version of the original article can be found at https://doi.org/10.1007/s43615-021-00047-8

Antreas Kantaros

akantaros@uniwa.gr

1 Department of Industrial and Product Design Engineering, University of West Attica, Athens, Greece 